\title{
Impact of electronic and blended learning programs for manual perineal support on incidence of obstetric anal sphincter injuries: a prospective interventional study
}

Hadil Ali-Masri ${ }^{1,2,3^{*}}$ (D), Sahar Hassan ${ }^{4}$, Erik Fosse ${ }^{2,3}$, Kaled M. Zimmo $5,2,3$, Mohammed Zimmo ${ }^{6,2,3}$, Khaled M. K. Ismail', Åse Vikanes ${ }^{2}$ and Katariina Laine ${ }^{8,9}$

\begin{abstract}
Background: Obstetric anal sphincter injuries (OASIS) are associated with anal incontinence, dyspareunia and perineal pain. Bimanual perineal support technique (bPST) prevents OASIS. The aim of this study was to assess the effect of two different bPST training-methods on OASIS incidence.

Methods: This is a prospective-interventional quality improvement study conducted in two Palestinian maternity units between June 12015 and December 31 2016. Women having spontaneous or operative vaginal-delivery at $\geq 24$ gestational-weeks or a birthweight of $\geq 1000 \mathrm{~g}(n=1694)$ were recruited and examined vaginally and rectally immediately after vaginal birth by a trained assessor. Data on baseline OASIS incidence were collected during Phase-1 of the study. Subsequently, birth attendants in both maternity units were trained in bPST using two training modalities. A self-directed electronic-learning (e-learning) using an animated video was launched in phase-2 followed by a blended learning method (the animated e-learning video+ structured face-to-face training) in phase-3. OASIS incidence was monitored during phases-2 and 3. Variations in OASIS incidence between the three phases were assessed using Pearson- $x^{2}$-test (or Fisher's-Exact-test). The impact of each training-method on OASIS incidence was assessed using logistic-regression analysis.
\end{abstract}

Results: A total of 1694 women were included; 376 in phase-1, 626 in phase-2 and 692 in phase-3. Compared to Phase-1, OASIS incidence was reduced by $45 \%$ (12.2 to $6.7 \%$, aOR: $0.56, \mathrm{Cl} ; 0.35-0.91, p=0.018)$ and $74 \%$ (12.2 to $3.2 \%, a \mathrm{OR}, 0.29, \mathrm{Cl} ; 0.17-0.50, p<0.001)$ in phases-2 and 3 , respectively. There was also a significant reduction in OASIS incidence by $52 \%$ from phase-2 to phase-3 (6.7\% (42/626) to $3.2 \%(22 / 692), p=0.003)$.

These reductions reached statistical significance among parous-women only (aOR: $0.18, \mathrm{Cl} ; 0.07-0.49, p=0.001$ ) after the first training method tested in phase-2. However, the reduction was significant among both primiparous (aOR: 0.39, $\mathrm{Cl} ; 0.21-0.74, p=0.004$ ) and parous-women (aOR: $0.11, \mathrm{Cl} ; 0.04-0.32, \mathrm{p}<0.001$ ) after implementing the blended learning method in phase-3.

Conclusion: The animated e-learning video had a positive impact on reducing OASIS incidence. However, this reduction was enhanced by the use of a blended learning program combining both e- learning and face-to-face training modalities.

Study registration number: ClinicalTrialo.gov identifier: NCT02427854, date: 28 April 2015.

Keywords: Animation, Blended, Face-to-face, manual, OASIS, Palestine, Perineum, Support, Training

\footnotetext{
* Correspondence: had_yousif@yahoo.ca

'Department of Obstetrics, Palestine Medical Complex, Ramallah, Palestine

${ }^{2}$ The Intervention Centre, Oslo University Hospital, Rikshospitalet, Oslo,

Norway

Full list of author information is available at the end of the article
}

C The Author(s). 2018 Open Access This article is distributed under the terms of the Creative Commons Attribution 4.0 International License (http://creativecommons.org/licenses/by/4.0/), which permits unrestricted use, distribution, and reproduction in any medium, provided you give appropriate credit to the original author(s) and the source, provide a link to the Creative Commons license, and indicate if changes were made. The Creative Commons Public Domain Dedication waiver (http://creativecommons.org/publicdomain/zero/1.0/) applies to the data made available in this article, unless otherwise stated. 


\section{Background}

Obstetric anal sphincter injuries (OASIS) are the leading cause of dyspareunia, perineal pain and female anal incontinence [1-3]. Recognition and suturing of OASIS require well-trained and experienced clinicians [4, 5]. Despite primary repair, between 15 to $61 \%$ of women who sustain OASIS still develop anal incontinence [2]. Furthermore, there is five times increased risk of recurrence of OASIS in a subsequent vaginal delivery [6]. In view of this, there have been several efforts to reduce OASIS occurrence by modifying intrapartum predisposing factors such as using vacuum instead of forceps and mediolateral instead of midline cut when episiotomy is indicated [5]. However, primiparity and macrosomia are among the prominent risk factors of OASIS, which cannot be modified $[7,8]$. Several studies have shown that protecting the perineum with the bimanual perineum support technique (bPST) or the "Finnish grip" plays an effective role in reducing OASIS incidence even in high risk births [9-11].

Mobile health education ( $\mathrm{m}$-health) has emerged as a fast and low-cost e-learning route, providing solutions to the challenges of training of health workers, particularly, in limited-resource settings [12]. More than $80 \%$ of the population living in rural areas has access to mobile devices [13], which seem to contribute to the improvement of healthcare including maternal healthcare, in many low-middle-income countries [14]. A recent systematic review has demonstrated the success of different $m$-health interventions undertaken in Sub-Saharan Africa, East and South Asia and in the Middle East, in improving the quality of antenatal and postnatal care, increasing awareness and knowledge of pregnant women, tracking vital signs and obstetric emergencies and also collecting pregnancy related data [15].

Blended-learning, which refers to a structured incorporation of electronic and face-to-face learning [16], has been shown to be an effective modality of training in different medical fields [17-19].

The main aim of this study was to assess the impact of two different training-methods on OASIS incidence; a stand-alone animated e-learning video providing practical instructions about bPST, and a blended learning modality involving the e-learning video as well as structured face-to-face training.

\section{Methods}

The reporting of this prospective quality-improvement interventional study followed the Standards for Quality Improvement Reporting Excellence (SQUIRE) 2.0 statement for quality-improvement studies. The study was conducted over 14 months, in the period between June 1st 2015 and December 31st 2016, within two governmental maternity units in Palestine. One maternity unit is located in the West Bank and the other in Gaza, with an average birth rate of $8000-10,000$ births per annum. The maternity unit in the West Bank is qualified as a training center for intern and resident doctors, medical students and midwifery students, while the Gaza unit does not provide similar training programs. In the participating maternity units, doctors are involved in high risk and instrumental deliveries while midwives manage the low risk deliveries. Episiotomy and perineal tears are usually assessed and repaired by doctors only. Vacuum is the only method used for operative vaginal delivery and right mediolateral episiotomy is the recommended episiotomy technique in both maternity units. Perineal protection is provided during crowning of the baby's head by placing the dominant hand flat on the posterior perineum while the other hand is used to protect the urethra. The mother is instructed to push with contractions only. Although this could be considered a form of bimanual perineal support, there are several inherent differences from bPST [9] where the non-dominant hand controls the speed of the delivery of the baby's head while the dominant hand supports the perineum in a way resembling a grip as the thumb and index fingers are placed on the lateral sides of the posterior perineum to squeeze towards the midline and the flexed middle finger supports the perineal body. Meanwhile, the need for an episiotomy is evaluated. Just before the delivery of the baby's head, the mother is instructed to stop pushing and wait for the uterine contractions to spontaneously deliver the head to avoid its sudden expulsion. Following delivery of the head, perineal support is continued during delivery of the shoulders (see Additional file 1). Women in this study did not receive antepartum training or education about the bPST. The technique and instructions were to be explained to the mother after admission just before the second stage of labor was approached.

We used two training-methods on two consecutive time periods; self-directed animated e-learning video and blended-learning (a combination of the animated e-learning video and the traditional face-to-face training).

\section{E-learning training package (training-method 1)}

A four-minute e-learning video $\subset$ (Additional file 1) was developed for this study. The video contains an introduction about obstetric perineal trauma and animated demonstration of bPST with voiceover in Arabic and English. Each maternity unit received two tablets with both video versions. These were wall-mounted in labor ward and staff meeting rooms of each of the participating units simultaneously. Birth attendants (doctors and midwives) were encouraged to watch the video as many times as they want, nevertheless, no assistance or explanations were provided. 


\section{Blended-learning training package (training-method 2)}

This included the previously described animated e-learning video and face-to-face training. The tablets were kept on site during and after the face-to-face training. One senior obstetrician (author KL) and two tutor midwives from Oslo University Hospital conducted the face-to-face training with the assistance of three local doctor research fellows (authors HAM, KZ and MZ) during which more than $90 \%$ (84 doctors and midwives) of birth attendants were trained. The structured face-to-face training consisted of an initial workshop run in two successive days in each of the two maternity units, to allow as many birth attendants as possible to be trained, where those who were working on the first day were able to attend in the second day and vice versa. The workshop included lectures on OASIS rates, diagnosis, risk factors and prevention, illustration of bPST and accurate technique of episiotomy when indicated followed by instructor-guided practical training on birthing simulators. The workshop was followed by a 10 day period of supervised real-life assessment and training in the labor rooms by the Norwegian tutor midwives; one midwife within each of the two maternity units.

\section{Study population}

The study population was selected randomly, reducing the risk of selection bias. Women were considered eligible for inclusion if they had a vaginal birth, were $\geq 24$ gestational weeks or had a baby with a birth weight $\geq$ $1000 \mathrm{~g}$, provided verbal consent to be examined and there was a trained assessor available on labor ward. All examinations were performed by one of the three research fellows (authors HAM, KZ and MZ), or one of four doctors working in the participating units, who were previously thoroughly trained in postnatal perineal assessment by the three research fellows [20]. The seven assessors were equally distributed throughout the study period; four assessors undertook the examinations in Gaza maternity unit and three assessors in the West Bank maternity unit. The trained assessors were not involved in the actual birth and three of them had pre-scheduled working hours while the other four were available at random times that the birth attendants could not predict. The assessment was only clinical involving both vaginal and rectal examinations, which took place during morning, evening or night shifts. The assessors were not blinded to whether the birth attendants had been trained or not after implementation of trainingmethod 2 but not after training-method 1 , as it was not possible to register and identify the birth attendants who had used the animated e-learning method.

The main outcome measure was OASIS incidence calculated as percent number of OASIS cases per number of total women examined in each of the study phases.
The definition and classification of OASIS were based on the diagnoses O70.2 and O70.3 in the ICD-10 system [21] as shown in Table 1.

The study was designed to run in three consecutive phases (Fig. 1).

In phase-1, 376 women were examined over four-month period prior to any bPST training interventions for baseline data on OASIS incidence.

In phase-2, 626 women were examined over a four-month period after the first training-intervention (animated e-learning video); to monitor possible effects on OASIS incidence.

In phase-3, 692 women were examined over a four month period after introducing the blended learning method (animated e-learning video and additional face-to-face training); in order to track the impact of the interventions on OASIS incidence.

\section{Data collection}

This study is a sub-study of a population based birth cohort study "Palestinian Perineum and Birth Complications Study". Data collection was previously described by Sahar et al. [22]. Birth attendants collected data prospectively during the three study phases, using paper and electronic case registration forms, identified by serial numbers. All data were then transferred to Service (Tjenester) for Sensitive Data (TSD) platform at University of Oslo (tsd-drift@usit.uio.no). The TSD platform is used by researchers working at the university and in other public research institutions to collect, store, analyze, and share sensitive data in compliance with the Norwegian regulations regarding individuals' privacy. Serial numbers designated to women, examined in this study, were obtained and subsequently used to retrieve their data which were de-identified at this stage.

\section{Statistics}

Based on data collected for baseline in phase-1, statistical power calculations were conducted, showing that at least 355 women were required in each study phase to demonstrate a $50 \%$ reduction in OASIS incidence after

\begin{tabular}{cl} 
Table 1 ICD-10 classification of perineal injuries \\
\hline Degree & Definition \\
\hline First & $\begin{array}{l}\text { Injury to vaginal mucosa or perineal skin only } \\
\text { Injury to vaginal mucosa or perineal skin and superficial } \\
\text { pecond }\end{array}$ \\
Third & Injury to anal sphincter muscles and subdivided into \\
$3 \mathrm{~A}$ & $<50 \%$ of external anal sphincter muscles is injured \\
$3 \mathrm{~B}$ & $>50 \%$ of external anal sphincter muscle is injured \\
$3 \mathrm{C}$ & External and internal anal sphincter muscles are injured \\
Fourth & $\begin{array}{l}\text { Injury involving external and internal anal sphincter } \\
\text { muscles and anal epithelium }\end{array}$ \\
\hline
\end{tabular}




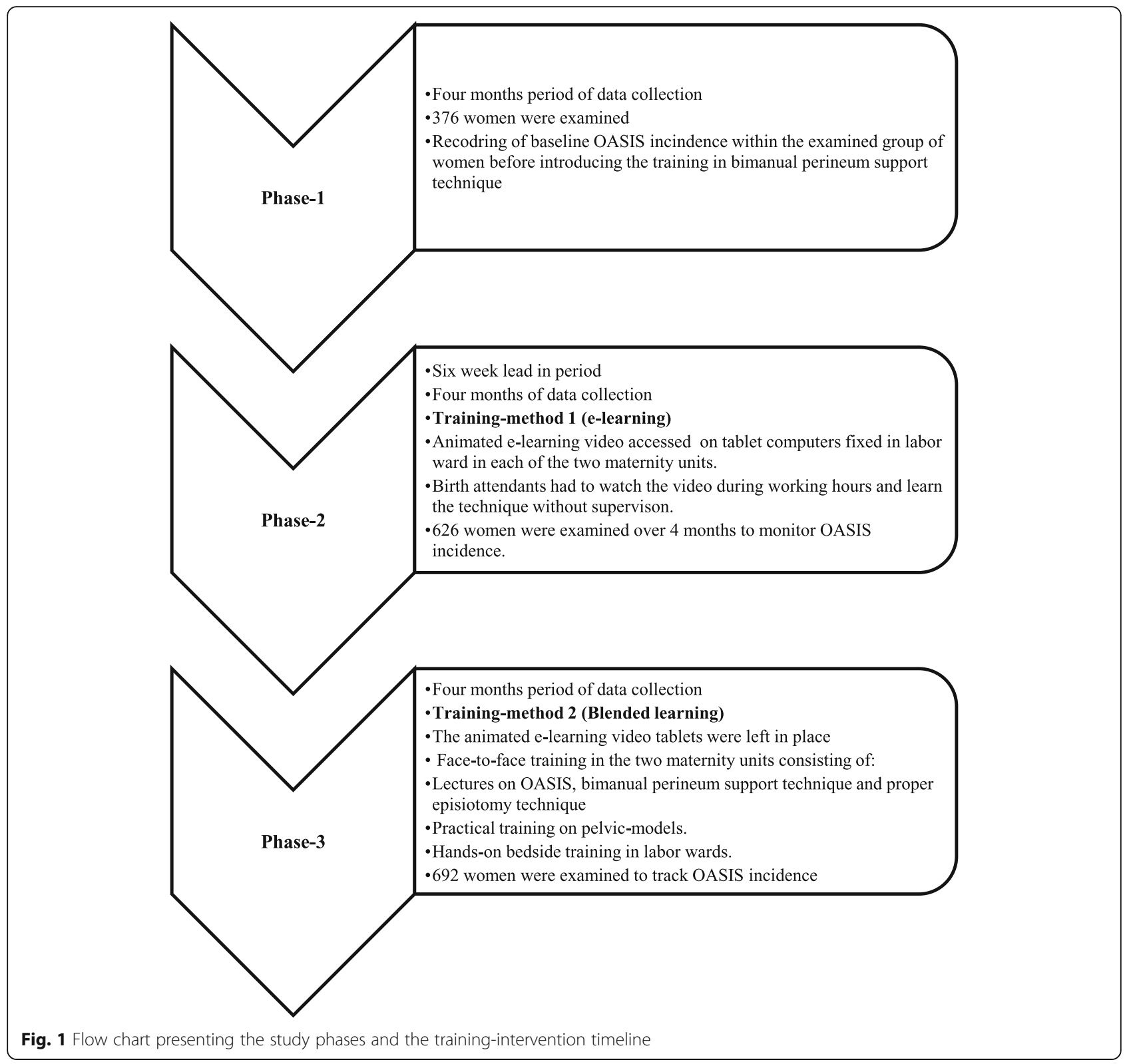

the training-interventions, given a statistical power of 80 and $95 \%$ confidence interval.

Categorical data were presented as frequencies and continuous data as means and standard deviations (SD). Body mass index (BMI), birthweight and duration of second stage of labor were categorized. Variations among the three study phases were assessed using One-Way-ANOVA-test for continuous and Pearson- $\chi^{2}$ or Fisher's-Exact tests (if cell counts $<5$ ) for categorical variables. Univariate analysis by $x^{2}$-test was performed to explore risk factors associated with OASIS. All risk factors with $p$ value $<0.2$ were used in the multiple logistic regression analysis to determine which factors were independently associated with OASIS in each phase. Accordingly, those significant risk factors were adjusted for using multiple regression analysis to determine the direct impact of the two training-methods on OASIS incidence and results were presented by adjusted OR (aOR) for OASIS with 95\% CI. The same analysis was repeated stratified according to parity. The significance level was set at $\mathrm{p}$ value $<5 \%$. The analyses were conducted using SPSS version 24.0 (IBM, Armonk, NY, USA).

\section{Results}

A total of 1694 women were included, among those $22.2 \%(n=376)$ were examined before the trainingintervention (phase-1), 36.9\% $(n=626)$ during phase-2 and $40.9 \%(n=692)$ during phase-3.

Clinical characteristics and perineal status in the three study phases are presented in Table 2 . 
Table 2 Clinical characteristics and perineal status of study population during the three study phases

\begin{tabular}{|c|c|c|c|c|}
\hline Characteristics & $\begin{array}{l}\text { Phase- } 1 \\
(N=376)\end{array}$ & $\begin{array}{l}\text { Phase-2 } \\
(\mathrm{N}=626)\end{array}$ & $\begin{array}{l}\text { Phase-3 } \\
(N=692)\end{array}$ & $P^{1}$ \\
\hline Age (years) & $25 \pm 5.0$ & $26 \pm 5.6$ & $27 \pm 5.7$ & $<0.001$ \\
\hline Gestational age & $39.0 \pm 1.6$ & $39.0 \pm 1.8$ & $39 \pm 1.8$ & 0.597 \\
\hline \multicolumn{5}{|l|}{$\mathrm{BMI}^{2}$} \\
\hline$<18.5$ & - & - & - & \\
\hline $18.5-24.99$ & $66(17.6)$ & $116(18.5)$ & $129(18.6)$ & \multirow[t]{4}{*}{0.887} \\
\hline $25-29.99$ & $198(52.7)$ & $313(50.0)$ & $346(50.0)$ & \\
\hline$\geq 30$ & $105(27.9)$ & $190(30.4)$ & $210(30.3)$ & \\
\hline Missing & $7(1.9)$ & $7(1.1)$ & $7(1.0)$ & \\
\hline Primiparous women & $195(51.9)$ & $279(44.6)$ & $256(37.0)$ & \multirow[t]{2}{*}{$<0.001$} \\
\hline Parous women & $181(48.1)$ & $347(55.4)$ & $436(63.0)$ & \\
\hline \multicolumn{5}{|l|}{ Method of vaginal birth } \\
\hline Spontaneous & $363(96.5)$ & $587(93.8)$ & $671(97.0)$ & \multirow[t]{2}{*}{0.011} \\
\hline Vacuum & $13(3.5)$ & $39(6.2)$ & $21(3.0)$ & \\
\hline \multicolumn{5}{|l|}{ Fetal presentation } \\
\hline Cephalic & $373(99.2)$ & $619(98.9)$ & $685(99.0)$ & \multirow[t]{3}{*}{0.663} \\
\hline Breech & $2(0.5)$ & $7(1.1)$ & $6(0.9)$ & \\
\hline Occiput posterior & $1(0.3)$ & $0(0.0)$ & $1(0.1)$ & \\
\hline \multicolumn{5}{|l|}{ Onset of labor } \\
\hline Spontaneous & $328(87.2)$ & $513(82.0)$ & $605(87.4)$ & \multirow[t]{2}{*}{0.010} \\
\hline Induced & $48(12.8)$ & $113(18.0)$ & $87(12.6)$ & \\
\hline \multicolumn{5}{|c|}{ Second stage duration (minutes) } \\
\hline$<30$ & $256(68.1)$ & $332(53.0)$ & $432(62.4)$ & \multirow[t]{4}{*}{$<0.001$} \\
\hline $30-59$ & $82(21.8)$ & $150(24.0)$ & $161(23.3)$ & \\
\hline$\geq 60$ & $22(5.9)$ & $81(12.9)$ & $64(9.2)$ & \\
\hline Missing & $16(4.3)$ & $63(10.1)$ & $35(5.1)$ & \\
\hline \multicolumn{5}{|l|}{ Birthweight (grams) } \\
\hline$<3000$ & $86(22.9)$ & $170(27.2)$ & $174(25.1)$ & \multirow[t]{4}{*}{0.848} \\
\hline $3000-3499$ & $172(45.7)$ & $269(43.0)$ & $309(44.7)$ & \\
\hline 3500-3999 & $93(24.7)$ & $145(23.2)$ & $167(24.1)$ & \\
\hline$\geq 4000$ & $25(6.6)$ & $42(6.7)$ & $42(6.1)$ & \\
\hline Intact Perineum & $152(40.4)$ & $325(52.0)$ & $426(61.6)$ & $<0.001$ \\
\hline Episiotomy & $134(35.6)$ & $166(26.5)$ & $124(18.0)$ & $<0.001$ \\
\hline First degree tear & $42(11.2)$ & 85 (13.6) & $93(13.4)$ & 0.492 \\
\hline Second degree tear & $54(14.4)$ & $72(11.5)$ & $98(14.2)$ & 0.276 \\
\hline OASIS $^{3}$ & $46(12.2)$ & $42(6.7)$ & $22(3.2)$ & $<0.001$ \\
\hline
\end{tabular}

- Categorical data were presented by $\mathrm{n} / \mathrm{N}(\%)$, and continuous variables by mean $\pm S D$

- $P^{1}$; differences were assessed by One-Way-ANOVA test for continuous variables and Pearson- $\chi^{2}$ test or Fisher's Exact test (for cells with counts $<5$ ) for categorical variables.

- $\mathrm{BMI}^{2}$; body mass index = maternal weight in kilograms $/(\text { height in meters })^{2}$ - $\mathrm{OASIS}^{3}$; obstetric anal sphincter injuries.
There were significant variations between the study phases in proportions of primiparous women (37.0$51.9 \%)$, vacuum assisted delivery (3.0-6.2\%), induced labor (12.6-18.0\%) and duration of second stage of labor $\geq 60(5.9-12.9 \%)$.

The OASIS incidence was reduced by $45 \%$ from phase- 1 to phase-2 $(12.2 \%(46 / 376)$ to $6.7 \%(42 / 626), p=0.004)$, by $52 \%$ from phase- 2 to phase-3 (6.7\% (42/626) to $3.2 \%$ (22/ 692), $p=0.003)$ and by $74 \%$ from phase- 1 to phase- 3 $(12.2 \%(46 / 376)$ to $3.2 \%(22 / 692), p<0.001)$. There was also a significant reduction in episiotomy rates and a significant increase of intact perineum proportions after implementing training-method 1 and 2 (Table 1).

Primiparity, birthweight $\geq 4000 \mathrm{~g}$ and duration second stage $\geq 60 \mathrm{~min}$ were associated with increased risk of OASIS. When applying multiple regression analysis, adjustment for parity, birthweight and duration of second stage did not change the effect of the two training-interventions on reducing OASIS incidence; training-method 1 (aOR: 0.56 , CI; 0.35-0.91, $p=0.018)$ and training-method 2 (aOR: 0.29 , CI; 0.17-0.50, $p<0.001)$.

\section{Primiparous women}

Compared to phase-1, phases- 2 and 3 had significantly larger proportions of women with prolonged second stage of labor $\geq 60 \min (25.8$ and $20.7 \%$ vs $11.3 \%$ ) and intact perineum ( 25.4 and $34.8 \%$ vs $18.0 \%$ ) and lower episiotomy rates (52.7 and $39.5 \%$ vs $64.6 \%)$ as shown in Table 3.

Vacuum assisted delivery and duration second stage of labor $\geq 60 \mathrm{~min}$ were associated with risk of OASIS in phase-1. No significant risk factors were identified in phase-2 or 3. Episiotomy, induction of labor, BMI, fetal presentation and birthweight were not associated with OASIS. Although OASIS incidence was reduced following training-method $1(12.5 \%(35 / 279)$ vs $15.9 \%$ (31/ 195)), this reduction was not statistically significant after adjusting for the identified significant risk factors associated with OASIS (vacuum assisted delivery and duration second stage of labor $\geq 60 \mathrm{~min}$ ); (aOR:0.81, CI; 0.47-1.4, $p=0.465)$. In contrast, the training-method 2 was associated with a significant reduction in OASIS incidence (6.6\% (17/256) vs. $15.9 \%$ (31/195), aOR: 0.39, CI; 0.21$0.74, P=0.004)$.

There was an increase in the incidence of second degree tears during phase- 3 which was independently associated with training-method 2 (aOR: 2.3, CI; 1.4-3.7, $p=0.002$ ) and episiotomy use (aOR:1.5, CI; 1.0-2.3, $p=0.033$ ).

\section{Parous women}

Table 4 shows clinical characteristics and perineal status among parous women before and after the training-interventions. OASIS incidence was significantly reduced from $8.3 \%(15 / 181)$ in phase-1 to $2.0 \%(7 / 347)$ in 
Table 3 Clinical characteristics and perineal status among primiparous women during the three study phases

\begin{tabular}{|c|c|c|c|c|c|c|}
\hline Characteristics & $\begin{array}{l}\text { Phase-1 } \\
(N=195)\end{array}$ & $P^{1}$ & $\begin{array}{l}\text { Phase-2 } \\
(N=279)\end{array}$ & $P^{2}$ & $\begin{array}{l}\text { Phase-3 } \\
(N=256)\end{array}$ & $P^{3}$ \\
\hline Age (years) & $23 \pm 4.0$ & 0.040 & $24 \pm 5.0$ & 0.328 & $23 \pm 5.0$ & 0.306 \\
\hline Gestational age (weeks) & $39 \pm 1.5$ & 0.333 & $39 \pm 1.6$ & 0.099 & $39 \pm 2.0$ & 0.022 \\
\hline \multicolumn{7}{|l|}{$\mathrm{BMI}^{4}$} \\
\hline$<18.5$ & - & & - & & - & \\
\hline $18.5-24.99$ & $46(23.6)$ & 0.543 & $67(24.0)$ & 0.171 & $49(19.1)$ & 0.471 \\
\hline $25-29.99$ & $99(50.8)$ & & $131(47.0)$ & & $141(55.1)$ & \\
\hline$\geq 30$ & $45(23.1)$ & & 77 (27.6) & & $64(25.0)$ & \\
\hline Missing & $5(2.6)$ & & $4(1.4)$ & & $2(0.8)$ & \\
\hline \multicolumn{7}{|l|}{ Method of vaginal birth } \\
\hline Spontaneous & $184(94.4)$ & 0.166 & $253(90.7)$ & 0.146 & $241(94.1)$ & $>0.999$ \\
\hline Vacuum & $11(5.6)$ & & $26(9.3)$ & & $15(5.9)$ & \\
\hline \multicolumn{7}{|l|}{ Fetal presentation } \\
\hline Cephalic & $193(99.0)$ & $>0.999$ & 277 (99.3) & 0.433 & $252(98.4)$ & 0.703 \\
\hline Breech & $1(0.5)$ & $>0.999$ & $2(0.7)$ & 0.433 & $4(1.6)$ & 0.395 \\
\hline Occiput posterior & $1(0.5)$ & 0.411 & - & 0.433 & - & 0.432 \\
\hline \multicolumn{7}{|l|}{ Onset of labor } \\
\hline Spontaneous & $161(82.6)$ & 0.447 & $222(79.6)$ & 0.040 & $221(86.3)$ & 0.292 \\
\hline Induced & $34(17.4)$ & & $57(20.4)$ & & $35(13.7)$ & \\
\hline \multicolumn{7}{|c|}{ Second stage duration (minutes) } \\
\hline$<30$ & $104(53.3)$ & $<0.001$ & $94(33.7)$ & 0.174 & $105(41.0)$ & 0.009 \\
\hline $30-59$ & $62(31.8)$ & & $78(28.0)$ & & $81(31.6)$ & \\
\hline$\geq 60$ & $22(11.3)$ & & $72(25.8)$ & & $53(20.7)$ & \\
\hline Missing & $7(3.6)$ & & $35(12.5)$ & & $17(6.6)$ & \\
\hline \multicolumn{7}{|l|}{ Birthweight (grams) } \\
\hline$<3000$ & $53(27.2)$ & 0.317 & $93(33.3)$ & 0.161 & $84(32.8)$ & 0.102 \\
\hline 3000-4399 & $85(43.6)$ & & $118(42.3)$ & & $121(47.3)$ & \\
\hline 3500-3999 & $47(24.1)$ & & $51(18.3)$ & & $45(17.6)$ & \\
\hline$\geq 4000$ & $10(5.1)$ & & $17(6.1)$ & & $6(2.3)$ & \\
\hline Intact Perineum & $35(18.0)$ & 0.057 & $71(25.4)$ & 0.023 & $89(34.8)$ & $<0.001$ \\
\hline Episiotomy & $126(64.6)$ & 0.011 & $147(52.7)$ & 0.002 & $101(39.5)$ & $<0.001$ \\
\hline First degree tear & $17(8.7)$ & 0.751 & $27(9.7)$ & 0.334 & $32(12.5)$ & 0.224 \\
\hline Second degree tear & 31 (15.9) & 0.396 & $53(19.0)$ & 0.018 & 71 (27.7) & 0.003 \\
\hline OASIS $^{5}$ & $31(15.9)$ & 0.346 & $35(12.5)$ & 0.028 & $17(6.6)$ & 0.002 \\
\hline
\end{tabular}

- Differences were assessed for each pair of the study phases

- Categorical data were presented by $\mathrm{n} / \mathrm{N}(\%)$, and continuous variables by mean $\pm \mathrm{SD}$

- Differences were assessed by independent $t$-test for continuous variables and Pearson- Pearson- $x^{2}$ test or Fisher's Exact test (for cells with counts $<5$ ) for categorical variables.

- $\mathrm{P}^{1}$; difference between phase-1 and phase-2, $\mathrm{P}^{2}$; difference between phase-2 and phase-3, $\mathrm{P}^{3}$; difference between phase-1 and phase-3.

- $\mathrm{BMI}^{4}$; body mass index = maternal weight in kilograms/(height in meters) ${ }^{2}$

- OASIS ${ }^{5}$; obstetric anal sphincter injuries.

phase-2 down to $1.1 \%(5 / 436)$ in phase-3. No significant variation in episiotomy rate was observed, but proportions of intact perineum were significantly higher and incidence of second degree tear were significantly lower after the two training methods compared to before (Table 3).
Adjusted risk factors for OASIS were episiotomy, BMI and duration of second stage of labor. Episiotomy was the only factor associated with an increased risk of OASIS (aOR: 3.8, CI; 1.2-12.1, $p=0.025$ ). Both training-methods had an effect on the odds for OASIS; training-method 1 (aOR: 0.18, CI; 0.07-0.49, $p=0.001$ ) 
Table 4 Clinical characteristics and perineal status among parous women during the three study phases

\begin{tabular}{|c|c|c|c|c|c|c|}
\hline Characteristics & $\begin{array}{l}\text { Phase-1 } \\
(N=181)\end{array}$ & $P^{1}$ & $\begin{array}{l}\text { Phase-2 } \\
(N=347)\end{array}$ & $P^{2}$ & $\begin{array}{l}\text { Phase-3 } \\
(N=436)\end{array}$ & $P^{3}$ \\
\hline Age (years) & $27 \pm 5.0$ & 0.012 & $28 \pm 5.0$ & 0.900 & $28 \pm 5.0$ & 0.008 \\
\hline Gestational age (weeks) & $39 \pm 1.7$ & 0.893 & $39 \pm 2.0$ & 0.519 & $39 \pm 2.0$ & 0.683 \\
\hline \multicolumn{7}{|l|}{$B M l^{4}$} \\
\hline$<18.5$ & - & & - & & - & \\
\hline $18.5-24.99$ & $20(11.0)$ & & $49(14.1)$ & & $80(18.3)$ & \\
\hline $25-29.99$ & $99(54.7)$ & 0.617 & $182(52.4)$ & 0.194 & $205(47.0)$ & 0.056 \\
\hline$\geq 30$ & $60(33.1)$ & & $113(32.6)$ & & $146(33.5)$ & \\
\hline Missing & $2(1.1)$ & & $3(0.9)$ & & $5(1.1)$ & \\
\hline \multicolumn{7}{|l|}{ Method of birth } \\
\hline Spontaneous & $179(98.9)$ & 0.101 & $334(96.3)$ & 0.037 & $430(98.6)$ & $>0.999$ \\
\hline Vacuum & $2(1.1)$ & & $13(3.7)$ & & $6(1.4)$ & \\
\hline \multicolumn{7}{|l|}{ Fetal presentations } \\
\hline Cephalic & $180(99.4)$ & & 342 (98.6) & 0.477 & $433(99.3)$ & \\
\hline Breech & $1(0.6)$ & 0.440 & $5(1.4)$ & 0.251 & $2(0.5)$ & $>0.999$ \\
\hline Occiput posterior & - & & - & $>0.999$ & $1(0.2)$ & \\
\hline \multicolumn{7}{|l|}{ Onset of labor } \\
\hline Spontaneous & $167(92.3)$ & 0.010 & $291(83.9)$ & 0.096 & $384(88.1)$ & 0.152 \\
\hline Induced & $14(7.7)$ & & $56(16.1)$ & & $52(11.9)$ & \\
\hline \multicolumn{7}{|c|}{ Second stage duration (minutes) } \\
\hline$<30$ & $152(84.0)$ & 0.001 & $238(68.6)$ & 0.505 & $327(75.0)$ & 0.006 \\
\hline $30-59$ & $20(11.0)$ & & $72(20.7)$ & & $80(18.3)$ & \\
\hline$\geq 60$ & - & & $9(2.6)$ & & $11(2.5)$ & \\
\hline Missing & $9(5.0)$ & & $28(8.1)$ & & $18(4.1)$ & \\
\hline \multicolumn{7}{|l|}{ Birthweight } \\
\hline$<3000$ & $33(18.2)$ & 0.626 & $77(22.2)$ & 0.907 & 90 (20.6) & 0.709 \\
\hline 3000-3499 & $87(48.1)$ & & $151(43.5)$ & & $188(43.1)$ & \\
\hline 3500-3999 & $46(25.4)$ & & $94(27.1)$ & & $122(28.0)$ & \\
\hline$\geq 4000$ & $15(8.3)$ & & $25(7.2)$ & & $36(8.3)$ & \\
\hline Intact Perineum & $117(64.6)$ & 0.045 & $254(73.2)$ & 0.210 & $337(77.3)$ & 0.001 \\
\hline Episiotomy & $8(4.4)$ & 0.681 & $19(5.5)$ & $>0.999$ & $23(5.3)$ & 0.694 \\
\hline First degree tear & $25(13.8)$ & 0.450 & $58(16.7)$ & 0.317 & $61(14.0)$ & $>0.999$ \\
\hline Second degree tear & $23(12.7)$ & 0.004 & $19(5.5)$ & 0.760 & $27(6.2)$ & 0.009 \\
\hline OASIS & $15(8.3)$ & 0.001 & $7(2.0)$ & 0.387 & $5(1.1)$ & $<0.001$ \\
\hline
\end{tabular}

- Differences were assessed between each pair of the study phases

- Categorical data were presented by $\mathrm{n} / \mathrm{N}(\%)$, and continuous variables by mean $\pm \mathrm{SD}$

- Differences were assessed by independent t-test for continuous variables and Pearson- Pearson- $\chi^{2}$ test or Fisher's Exact test (for cells with counts< 5 ) for categorical variables

- $\mathrm{P}^{1}$; difference between phase-1 and phase- $2, \mathrm{P}^{2}$; difference between phase-2 and phase- $3, \mathrm{P}^{3}$; difference between phase- 1 and phase-3

- $\mathrm{BMI}^{4}$; body mass index = maternal weight in kilograms/(height in meters) ${ }^{2}$

- OASIS ${ }^{5}$; obstetric anal sphincter injuries

and training-method 2 (aOR: 0.11, CI; 0.04-0.32, $p<$ $0.001)$.

\section{Discussion}

This study has shown a significant reduction in OASIS incidence after introducing bPST using animated e- learning video alone or combined with face-to-face training. The blended learning methodology reduced OASIS incidence by two thirds, and was almost twice as effective as the e-learning video alone. Moreover, while the impact of the blended learning was statistically significant among primiparous and parous women, the 
effect of the animated video alone was only significant among parous women.

Changes in the clinical characteristics and risk factors between the three study phases do not explain the rapid reduction in OASIS incidence.

Non-blinded clinical studies could influence clinical practice. However, the transient increase in the rate of the operative delivery during phase- 2 is believed to be random and independent of the training interventions. The two training methods were specifically focused and hence are not believed to have influenced other intrapartum management protocols throughout the study period.

Nilsson et al. [23], demonstrated that video-training in the management of postpartum hemorrhage was as effective as hands-on training in a secondary health care in Kenya. However, those who participated in that study were senior nursing students who were more likely to be familiar with postpartum hemorrhage management as part of their curriculum. In contrast, birth attendants in our setting were not aware of bPST prior to this study. Training-method 1 required the birth attendants to learn directly from the animated e-learning video without a supervisor. Hence, the supervised training and interactive discussions related to problems encountered during the use of the technique are not possible using the animated video alone. The combination of e-learning and traditional face-to-face training has become popular enabling integration of theoretical knowledge and clinical practice [24].

There are several plausible explanations for the differences in the effects of the two tested training methods. We have previously shown that the animated e-learning video has been approved as a clear and comprehensible tool feasible to use as an independent training method [25]. It is possible that birth attendants did not get the opportunity to see the video repeatedly until they feel competent to use bPST, which is necessary for this tool to achieve its maximum effect. Indeed, frequent exposure to the same instructional material has been found to be associated with better learning outcomes [26], but the work overload in our clinical setting may not have made watching the video frequently possible. Clinicians often utilize their smart mobile devices for professional tasks [27], hence making the training video available on this platform could enhance its dissemination by enabling birth attendants to watch the video at their convenience [28]. Secondly, it is well documented that changing clinical practice is often faced by resistance and delayed adoption [29]. It is possible that initially, birth attendants were not fully engaged in the animation-based training since they had no prior education about the clinical effectiveness of bPST, something that is believed to hinder its use [25]. The blended learning modality enabled birth attendants to see and speak to experts in the field, which could have bridged the engagement gap and resulted in a substantial reduction in OASIS incidence during phase-3. In support of our study findings is the reporting of a recent systematic review that blended learning is equally or more effective than self-directed e-learning [30]. However, in that review, the effect of the different learning modalities focused on improving health professionals' knowledge rather than evaluating their clinical competencies. Although there is some evidence of clinical skills' improvement as a result of engaging blended learning [24], the variation in clinical contexts and the diversity of learning approaches highlight the need for more concrete research on the role of blended learning in the actual clinical scenarios [24].

There is still debate about the role of hands-on support of the perineum in the prevention of severe obstetric trauma. A recent update of a Cochrane systemic review has reported that the hands-on perineum support has no effect on OASIS risk compared to the hands-off method [31]. Nevertheless, the low quality of the included studies and the heterogeneity of the studied perineal support techniques did not provide robust evidence. Our findings, however, are in line with earlier studies' reporting that the bPST is effective at reducing severe perineal trauma [911, 32-34]. Implementation of the bPST has resulted in more than $50 \%$ reduction of OASIS incidence from 4 to $1.9 \%$ in Norway and from 7 to $3.4 \%$ in Denmark, respectively $[9,11]$. In the UK, the incidence of major OASIS (third degree $\mathrm{c}$ and fourth degree tears) was significantly reduced after the use of bPST [10].

It has been reported that the hands-on technique is associated with higher episiotomy rate than the hands-off technique [30]. In this study, we observed a marked reduction of episiotomy rate among primiparous women after implementing the bPST. One explanation may be that both training-interventions in this study included teaching that episiotomy should be done on indication only, which is particularly important for primiparous women in Palestine who are often being cut. In addition, we observed an increase in the incidence of spontaneous second degree tears after the training-intervention among primiparous women which was independent of the concomitant reduction in episiotomy rate, but could be argued to be due to the reduced severity of perineal lacerations (less extension to the anorectal complex) as a result of using the bPST [10].

\section{Strengths and limitations}

Our study has several strengths which support the generalizability of its findings. This is the first study where the effect of bPST is studied in a lowmiddle-income country. The animated e-learning video is a new training tool that has not been tested in clinical setting before but it was evaluated by experts and 
generalist doctors and midwives in a previous study and found suitable for teaching purposes [24]. We have included only women examined by doctors who were well-trained in the assessment of obstetric perineal trauma. We believe that the assessment by the same personnel, who were independent to the actual birth, before and after the interventions mitigated bias related to variations in the diagnostic skills and clinical experience of the examiners. In addition, women included in this study were not examined at fixed times but randomly based on when the assessors showed up which reduced the risk of selection bias.

However, we also recognize that the study has some limitations. Firstly, preliminary power sample calculations were conducted based on previously reported international estimates since there were no previous accurate data of OASIS incidence in Palestine. However, the OASIS incidence observed during phase-1 was much higher than estimated and hence the power sample size calculations were reviewed based on the collected baseline incidence. Also, the statistical calculation was not stratified by parity and hence this might have masked significant variations before and after the interventions. Secondly, there were missing data in some variables (BMI and duration of second stage of labor). However, the missing data were random and were not considered to affect the studied exposure-outcome associations. Finally, this was designed as a pragmatic study and hence, we did not collect information about whether bPST was used during the birth or not. It is highly possible that some of the women, examined after the interventions, did not have bPST at birth which might have underestimated the impact of the training methodology.

\section{Conclusions}

Blended learning methodology for bPST training was most effective in reducing OASIS incidence. However, the animated video is considered a promising independent training tool if the combined method is not feasible. Despite the challenging conditions in our setting, the animated video has independently contributed to the reduction in OASIS incidence. Therefore, we believe that such modality is a useful alternative particularly in limited resource healthcare settings. Integration of both training methods in the curriculum of doctors' and midwives' training programs under supervision of local trainers, has been set as a future strategy to sustain the impact of the quality improvement intervention.

\section{Additional file}

Additional file 1: animation video.mp4. Length: $4 \mathrm{~min}$ and $43 \mathrm{~s}$, size: 18.5 MB. Copyright holder: Oslo University Hospital 2015 @. Permission to use the video was granted as the animation was designed by the authors $\mathrm{KL}$ and $\AA \mathrm{V}$ to be used in this study only. The copyright was registered under the name of the funding facilitator. (MP4 $18988 \mathrm{~kb}$ )

\section{Abbreviations}

bPST: Bimanual perineum support technique; OASIS: Obstetric anal sphincter injuries

\section{Acknowledgements}

We acknowledge Ala' Hamid and Hasan Alsalman for their vital assistance and contribution in examination of women in this study. We thank the midwives Cicecilie Lødval and Kristin Næs-Andresen who contributed to the face-to-face training. We also thank Jon Michael Gran for his assistance in statistical analysis.

\section{Funding}

This study was funded by the Norwegian Research Council (grant number: 234452). The funding source had no role in the study design, data collection, analysis and interpretation or in the writing of the manuscript.

\section{Availability of data and materials}

The dataset generated and analyzed during the current study is not publicly available. Based on the recommendations of the data inspectorate, the dataset of this study is stored in a secure platform (Service for Sensitive Data (TSD)) owned by the University of Oslo. TSD facilities are developed and operated by TSD service group at IT-Department of the University of Oslo (tsd-drift@usit.uio.no). Access to this platform requires special permission given to researchers working at the university and in other public research institutions to collect, store, analyze, and share sensitive data in compliance with the Norwegian regulations regarding individuals' privacy.

\section{Authors' contributions}

All authors have read and approved the last version of the manuscript. HAM: Wrote the manuscript and contributed to the implementation of the training-intervention, examination of women included in the study, data collection and statistical analysis. SH: Contributed to project development, planning of the training-intervention, data collection and critical comments on the manuscript. EF: Contributed to project development, study design and revision of the manuscript. KZ: Contributed to implementation of the training-intervention, data collection, examination of included women and revision of the manuscript. MZ: Contributed to implementation of the training-intervention, data collection, examination of included women and revision of the manuscript. Kl: Contributed to study concept and design, critical revision and comments on the manuscript for intellectual content. $\AA \mathrm{V}$ : Contributed to project development, implementation of the trainingintervention and critical comments on the manuscript. $\mathrm{KL}$ : contributed to study concept and design, project development, delivering the face-to-face training, data analysis and critical comments on the manuscript.

\section{Ethical approval and consent to participate}

The Palestinian health research council (Reference no.: BHRC $\mathrm{HC} \backslash 13 \backslash 15)$, the Regional Committee for Medical and Health Research Ethics in South-Eastern Norway (REK 2014/1727) and the Norwegian Data Inspectorate (17/00082-2/ GRA) reviewed and approved this study as health-quality research which can be implemented within the ordinary health services arrangements; as long it is done in accordance with common rules for health care services in Palestine and Norway regarding confidentiality and privacy. Due to political, cultural and practical challenges, the three ethics committees considered verbal consent valid as the advantages of the study exceeded the disadvantages of not having a written consent. Each woman provided a verbal consent before the study form was filled for her and before she was examined rectally or vaginally, knowing that she would receive the same care if she declined to any of these.

Consent for publication

Not applicable. No individual personal data were included. 


\section{Publisher's Note}

Springer Nature remains neutral with regard to jurisdictional claims in published maps and institutional affiliations.

\begin{abstract}
Author details
'Department of Obstetrics, Palestine Medical Complex, Ramallah, Palestine.

${ }^{2}$ The Intervention Centre, Oslo University Hospital, Rikshospitalet, Oslo, Norway. ${ }^{3}$ Institute of Clinical Medicine, Faculty of Medicine, University of Oslo, Oslo, Norway. ${ }^{4}$ Faculty of Pharmacy, Nursing and Health Professions, Birzeit University, Ramallah, Palestine. ${ }^{5}$ Department of Obstetrics, Al Aqsa Martyrs Hospital, Gaza, Palestine. 'Department of Obstetrics, Al Shifa Hospital, Gaza, Palestine. ${ }^{7}$ Department Obstetrics and Gynaecology, Ain Shams University, Cairo, Egypt. ${ }^{8}$ Department of Obstetrics, Oslo University Hospital, Ullevål, Oslo, Norway. ${ }^{9}$ Department of Health Management and Health Economics, Institute for Health and Society, University of Oslo, Oslo, Norway.
\end{abstract}

\section{Received: 19 April 2018 Accepted: 29 October 2018}

\section{Published online: 12 November 2018}

\section{References}

1. Sundquist JC. Long-term outcome after obstetric injury: a retrospective study. Acta Obstet Gynecol Scand. 2012;91(6):715-8. https://doi.org/10.1111/ j.1600-0412.2012.01398.x.

2. Fernando RJ, Sultan AH, Kettle C, Thakar R. Methods of repair for obstetric anal sphincter injury. Cochrane Database Sys Rev. 2013. https://doi.org/10. 1002/14651858.CD002866.pub3.

3. Laine K, Skjeldestad FE, Sanda B, Horne H, Spydslaug A, Staff AC. Prevalence and risk factors for anal incontinence after obstetric anal sphincter rupture. Acta Obstet Gynecol Scand. 2011;90(4):319-24. https://doi.org/10.1111/j. 1600-0412.2010.01057.x.

4. Andrews $V$, Sultan AH, Thakar R, Jones PW. Occult anal sphincter injuries-myth or reality? BJOG. 2006;113(2):195-200.

5. Harvey MA, Pierce M, Alter JE, Chou Q, Diamond P, Epp A, et al. Obstetrica anal sphincter injuries (OASIS): prevention, recognition, and repair. J Obstet Gynaecol Can. 2015;37(12):1131-48.

6. Edozien LC, Gurol-Urganci I, Cromwell DA, Adams EJ, Richmond DH Mahmood TA, et al. Impact of third- and fourth-degree perineal tears at first birth on subsequent pregnancy outcomes: a cohort study. BJOG. 2014; 121(13):1695-703. https://doi.org/10.1111/1471-0528.12886.

7. Eskandar O, Shet D. Risk factors for 3rd and 4th degree perineal tear. J Obstet Gynaecol. 2009;29(2):119-22. https://doi.org/10.1080/ 01443610802665090

8. Christianson LM, Bovbjerg VE, McDavitt EC, Hullfish KL. Risk factors for perineal injury during delivery. Am J Obstet Gynecol. 2003;189(1):255-60.

9. Laine K, Skjeldestad FE, Sandvik L, Staff AC. Incidence of obstetric anal sphincter injuries after training to protect the perineum: cohort study. BMJ Open. 2012;2(5). https://doi.org/10.1136/bmjopen-2012-001649.

10. Naidu M, Sultan AH, Thakar R. Reducing obstetric anal sphincter injuries using perineal support: our preliminary experience. Int Urogynecol J. 2017; 28(3):381-9. https://doi.org/10.1007/s00192-016-3176-4.

11. Rasmussen OB, Yding A, Anh ØJ, Sander Andersen C, Boris J. Reducing the incidence of obstetric sphincter injuries using a hands-on technique: an interventional quality improvement project. BMJ Qual Improv Rep. 2016;5(1). https://doi.org/10.1136/bmjquality.u217936.w7106 eCollection 2016.

12. mHealth Education. Harnessing the Mobile revolution to bridge the Health Education \& Training gap in developing countries. In: Report for mHealthEd 2011 at the Mobile health summit; 2011. www.mhealthknowledge.org/sites/ default/files/20_iheedreport_2011.pdf.

13. International Telecommunication Union. The World in 2010: ICT facts and figures. 2010. https://www.itu.int/ITU-D/ict/facts/2011/material/ ICTFactsFigures2011.pdf.

14. World Bank ICT Division. The role of mobile phones in sustainable rural poverty reduction. 2008. siteresources.worldbank.org/The_Role_of_Mobile_ Phones_in_Sustainable_Rural_Poverty_Reduction_June_2008.pdf.

15. Feroz A, Perveen $\mathrm{S}, \mathrm{Aftab}$ W. Role of $\mathrm{mHealth}$ applications for improving antenatal and postnatal care in low and middle income countries: a systematic review. BMC Health Serv Res. 2017;17(1):704

16. Garrison DR, Kanuka H. Blended learning: uncovering its transformative potential in higher education. Internet High Educ. 2004;7(2):95-105. https:// doi.org/10.1016/j.iheduc.2004.02.001.
17. Kho M, Chew K, Azhar M, Hamzah M, Chuah K, Bustam A, et al. Implementing blended learning in emergency airway management training: a randomized controlled trial. BMC Emerg Med. 2018;18(1). https://doi.org/ 10.1186/s12873-018-0152-y.

18. Coyne E, Rands H, Frommolt V, Kain V, Plugge M, Mitchell M. Investigation of blended learning video resources to teach health students clinical skills: an integrative review. Nurse Educ Today. 2018;63:101-7. https://doi.org/10. 1016/j.nedt.2018.01.021.

19. Howlett D, Vincent T, Watson G, Owens E, Webb R, Gainsborough N, et al. Blending online techniques with traditional face to face teaching methods to deliver final year undergraduate radiology learning content. Eur J Radiol. 2011;78(3):334-41. https://doi.org/10.1016/j.ejrad.2009.07.028.

20. Ali-Masri H, Hassan S, Ismail K, Zimmo K, Zimmo M, Fosse E, et al. Enhancing recognition of obstetric anal sphincter injuries in six maternity units in Palestine: an interventional quality improvement study. BMJ Open. 2018; 8(6):e020983. https://doi.org/10.1136/bmjopen-2017-020983.

21. Roos AM, Thakar R, Sultan AH. Outcome of primary repair of obstetric anal sphincter injuries (OASIS): does the grade of tear matter? Ultrasound Obstet Gynecol. 2010;36:368-74. https://doi.org/10.1002/uog.7512.

22. Hassan S, Vikanes A, Laine K, Zimmo K, Zimmo M, Bjertness E, et al. Building a research registry for studying birth complications and outcomes in six Palestinian governmental hospitals. BMC pregnancy childbirth. 2017;17(1): 112. https://doi.org/10.1186/s12884-017-1296-6.

23. Nilsson C, Sørensen BL, Sørensen JL. Comparing hands-on and video training for postpartum hemorrhage management. Acta Obstet Gynecol Scand. 2014;93(5):517-20. https://doi.org/10.1111/aogs.12372.

24. Rowe M, Frantz J, Bozalek V. The role of blended learning in the clinical education of healthcare students: a systematic review. Med Teach. 2012; 34(4):e216-21. https://doi.org/10.3109/0142159X.2012.642831.

25. Ali HY, Vikanes $\AA$, Anti M, Hassan S, Ismail KM, Zimmo K, et al. Evaluation of an animated instructional video as a training tool for manual perineum support during vaginal delivery. Int J Gynaecol Obstet. 2017;137(2):213-9. https://doi.org/10.1002/ijgo.12115.

26. Cook DA, Levinson AJ, Garside S, Dupras DM, Erwin PJ, Montori VM Instructional design variations in internet-based learning for health professions education: a systematic review and meta-analysis. Acad Med. 2010 May:85(5):909-22. https://doi.org/10.1097/ACM.0b013e3181d6c319.

27. Kho A, Henderson LE, Dressler DD, Kripalani S. Use of handheld computers in medical education. A systematic review J Gen Intern Med. 2006;21(5): $531-7$.

28. Jones MJ. Just-in-time training. Adv Dev Hum Resour. 2001;3:480-7.

29. Cabana MD, Rand CS, Powe NR, Wu AW, Wilson MH, Abboud PA, et al. Why don't physicians follow clinical practice guidelines? A framework for improvement. JAMA. 1999:282(15):1458-65.

30. Liu Q, Peng W, Zhang F, Hu R, Li Y, Yan W. The effectiveness of blended learning in health professions: systematic review and meta-analysis. J Med Internet Res. 2016;18(1):e2. https://doi.org/10.2196/jmir.4807.

31. Aasheim V, Nilsen ABV, Reinar LM, Lukasse M. Perineal techniques during the second stage of labour for reducing perineal trauma. Cochrane Database Syst Rev. 2017;6:CD006672. https://doi.org/10.1002/14651858. CD006672.pub3

32. Laine K, Pirhonen T, Rolland R, Pirhonen J. Decreasing the incidence of anal sphincter tears during delivery. Obstet Gynecol. 2008;111(5):1053-7. https:// doi.org/10.1097/AOG.0b013e31816c4402.

33. Hals E, Øian P, Pirhonen T, Gissler M, Hjelle S, Nilsen EB, et al. A multicenter interventional program to reduce the incidence of anal sphincter tears. Obstet Gynecol. 2010;116(4):901-8. https://doi.org/10.1097/AOG. Ob013e3181eda77a.

34. Bulchandani S, Watts E, Sucharitha A, Yates D, Ismail KM. Manual perineal support at the time of childbirth: a systematic review and meta-analysis. BJOG. 2015;122(9):1157-65. https://doi.org/10.1111/1471-0528.13431. 